\title{
RESEARCH
}

\section{CLINICAL CHARACTERISTICS AND FACTORS AFFECTING MORTALITY IN ELDERLY PATIENTS ADMITTED TO RESPIRATORY INTENSIVE CARE UNIT}

Turkish Journal of Geriatrics DOI: 10.31086/tjgeri.2020.134 2020; 23(1): 27-34
- Onur YAZICl ${ }^{1}$ iD
- Emel CEYLAN ${ }^{1}$ D
- Mehmet POLATLI ${ }^{1}$ iD
n Şule TAŞ GÜLEN ${ }^{1}$ iD
n Fisun KARADAĞ ${ }^{1}$ (D)

CORRESPONDANCE

Onur YAZICI

Adnan Menderes University, Faculty of Medicine, Department of Chest Diseases, Aydin, TURKEY.

Phone: +905331707929

e-mail: dronur_yazici@hotmail.com

Received: 01/11/2019

Accepted: 28/01/2020

${ }^{1}$ Adnan Menderes University, Faculty of

Medicine, Department of Chest Diseases, Aydin, TURKEY.

\section{Abstract}

Introduction: The number of geriatric patients being followed up in intensive care units (ICUs) has increased because of increased elderly population in our country and worldwide. This study aimed to investigate the clinical/laboratory features of patients aged over 65 years hospitalized in respiratory ICUs and to ascertain factors affecting mortality.

Materials and Method: Patients hospitalized in the respiratory ICU of Adnan Menderes University Medical Faculty between January 1, 2017 and January 1, 2018 were included. Patients aged 65 years and over were classified as the Elderly group, whereas those aged under 65 years were classified as the Non-Elderly group. The groups were compared for demographic, clinical, and laboratory characteristics. Parameters affecting mortality in the Elderly group were also evaluated.

Results: The mean age of 57 patients in the Non-Elderly group was $55.15 \pm$ 9.57 years, and that of 101 patients in the Elderly group was $76.55 \pm 7$ years. In the Elderly group, urea and creatine levels were higher and $\mathrm{pH}$ was lower; the predicted mortality rate and Acute Physiology and Chronic Health Evaluation (APACHE) II score were higher; however, mortality rates were similar. Factors affecting mortality were hypoalbuminemia, high APACHE II score, and vasopressor requirement.

Conclusion: The albumin level, APACHE II score, and VP requirement are more important for prediction of mortality in respiratory intensive care patients when compared to age.

Key Words: Geriatrics; Mortality; APACHE. 


\section{INTRODUCTION}

Human lifespan has concurrently prolonged with improvements in the field of health in the last century, which has progressively increased the number of elderly individuals (1). In Turkey, the population aged 65 years and over has increased by $16 \%$ in the last 5 years and reached $8.8 \%$ of the total population in 2018. It is estimated that this figure will be $10.2 \%$ by 2023 (2). With an increase in the elderly population, the frequency of presentation of elderly patients to health institutions, and therefore, hospitalization in either a hospital or ICUs has increased (3). Approximately $27 \%$ of the hospitalized patients aged 65 years and over have a requirement for ICU follow-up, and $21 \%-51 \%$ of patients admitted to ICUs are in the elderly age group $(4,5)$. In our country, there is a progressively increasing interest in data related to elderly population hospitalized in ICUs; however, the number of studies on this subject is limited (6-8).

We aimed to evaluate the demographic, clinical, and laboratory characteristics of elderly patients hospitalized and followed up in respiratory ICU and to ascertain factors affecting mortality in the elderly patients.

\section{MATERIALS AND METHOD}

The study was conducted by retrospective evaluation of data of 179 patients hospitalized in the respiratory ICU of Adnan Menderes University Medical Faculty between January 1, 2017 and January 1, 2018. The study was approved by the Non-invasive Clinical Research Ethics Committee of Adnan Menderes University, Turkey (Protocol number: 2019/97). The informant consent was not obtained because of the retrospective nature of the study. After excluding 21 patients with either missing data or an ICU stay less than 24 h, 158 patients were included in the study. The patients aged under 65 years were categorized as the Non-Elderly group and those aged 65 years and over as the Elderly group. Data of the patients such as age, gender, body mass index (BMI), comorbidities, diagnosis, the type and duration of ventilator treatment, vasopressor (VP) requirement, duration of hospitalization in ICU, the Acute Physiology and Chronic Health Evaluation (APACHE) II score, predicted mortality rate, and whether mortality had occurred or not were recorded. The APACHE II scoring system is one of the systems used in the determination of mortality rate and efficacy of treatment in ICUs (9). For calculating the APACHE II score, the most abnormal values obtained in the ICU within the first $24 \mathrm{~h}$ were considered. In addition to age, body temperature, mean arterial pressure, heart rate, respiratory rate, oxygenation (when fraction of inspired oxygen $(\mathrm{FiO} 2) \geq 0.5$, alveolar-arterial gradient; when $\mathrm{FiO} 2<0.5$, partial oxygen pressure $(\mathrm{PaO} 2))$, serum bicarbonate $(\mathrm{HCO} 3)$ value, serum sodium, potassium, and creatinine values, leukocyte count, hematocrit value, and the Glasgow Coma Scale score were used. The APACHE II score and the predicted mortality rate were calculated using computer software.

The biochemical parameters involving urea, creatine, alanine aminotransferase, aspartate aminotransferase, total bilirubin, direct bilirubin, protein, and albumin; the hematological parameters involving leukocyte, neutrophil, and lymphocyte counts, neutrophil/lymphocyte ratio (NLR), hemoglobin $(\mathrm{Hb})$, platelet count, mean platelet volume (MPV), and red cell distribution width (RDW); and the blood gas parameters of the patients such as $\mathrm{pH}, \mathrm{PaO} 2$, partial carbon dioxide pressure, oxygen saturation and $\mathrm{HCO} 3$, and also $\mathrm{C}$-reactive protein (CRP), and procalcitonin values were recorded.

\section{Statistical Analysis}

Descriptive statistics for quantitative variables were specified as mean \pm standard deviation for normally distributed variables and as median (25th-75th percentiles) for non-normally distributed variables. Descriptive statistics for qualitative variables were specified as frequency (\%). Comparison between quantitative variables was analyzed by conducting Student t- or Mann-Whit- 
ney U-test. The dependence between qualitative variables was determined by chi-square analysis. Logistic regression (LR) analysis was used to determine factors affecting mortality. A $p<0.05$ was considered statistically significant.

\section{RESULTS}

The mean age of the patients was $55.15 \pm 9.57$ years in the Non-Elderly group and $76.55 \pm 7$ years in the Elderly group, consisting of 57 patients and 101 patients, respectively. Forty-one (71.9\%) non-elderly patients and 69 (68.3\%) elderly patients were male $(p=0.635)$. The two groups were similar in terms of BMls $(p=0.439)$. The most common indications for hospitalization in both groups were pneumonia and exacerbation of chronic obstructive pulmonary disease (COPD) $(p=0.770$ and $p=0.655$, respectively). The presence of comorbidities had similar and very high rates in both groups (Non-Elderly group: 94.7\%, Elderly group: 94.1\%; $p=0.583$ ). COPD, hypertension, and diabetes mellitus were the most common comorbidities in both groups, and the incidence of the comorbidities except that of heart failure (HF) was similar in both groups $(p>0.05)$. The incidence of $\mathrm{HF}$ was significantly higher in the Elderly group ( $\mathrm{p}$ $=0.006$ ) than in the Non-Elderly group. The mean duration of hospitalization was $14.68 \pm 12.89$ days in the Non-Elderly group and $16.43 \pm 14.82$ days in the Elderly group. Even though the duration of hospitalization was found to be relatively longer in the Elderly group, a statistically significant difference between the two groups was not present ( $p$ $=0.580$ ). Invasive mechanical ventilation (IMV) was performed in 31 (54.4\%) patients in the Non-Elderly group and in 46 (45.6\%) in the Elderly group ( $p$ $=0.286$ ). The mean number of days that the patients were kept intubated was $11.64 \pm 10.05$ days in the Non-Elderly group and $14.34 \pm 16.77$ days in the Elderly group $(p=0.685)$. Non-invasive mechanical ventilation (NIMV) was performed in 35 (61.4\%) patients in the Non-Elderly group and in $74(73.3 \%)$ in the Elderly group ( $p=0.122)$. NIMV was performed for an average of $9.42 \pm 10.03$ days in the Non-Elderly group and for an average of $11.31 \pm 8.68$ days in the Elderly group $(p=0.190)$. While VP requirement occurred in 11 (19.3\%) of non-elderly patients during their follow-up period, it was detected in 26 (27.7\%) patients in the Elderly group ( $p=0.358)$. The predicted mortality rate and the APACHE II score calculated during admission to the ICU were statistically significantly higher in the Elderly group $(p=0.010$ and $p=$ 0.008 , respectively) then in the Non-Elderly group. Mortality occurred in 14 (24.6\%) patients in the Non-Elderly group and in 30 (29.7\%) patients in the Elderly group $(p=0.489)$. Demographic data of the patients are shown in Table 1.

Among the hematological, biochemical, and blood gas parameters analyzed during admissions of both groups of patients to the ICU, the urea and creatine values were statistically significantly higher, and the $\mathrm{pH}$ value was significantly lower in the Non-Elderly group compared with the Elderly group ( $p=0.004, p=0.002$, and $p=0.036$, respectively). The two groups were similar with respect to all the remaining parameters (Table 2).

When LR analysis was performed to determine the factors affecting mortality, hypoalbuminemia, increased APACHE II score, and VP requirement were found to be associated with mortality (sensitivity $63.3 \%$, specificity $95.5 \%$, and overall accuracy rate $83.2 \%$ ) (Table 3 ).

\section{DISCUSSION}

The number of elderly patients followed up in ICUs has been progressively increasing because of an increased elderly population (3-5). In our study, $63.9 \%$ of patients in the respiratory ICU were aged 65 years and over. The ratio of elderly patients followed in ICUs differs from study to study conducted in our country. For example, Topeli et al. (6), in their study, reported that $48.6 \%$ of patients followed in ICU were aged 65 years and over; whereas, Doğan et al. reported it as $51 \%$ and Uysal et al. 
Table 1. The demographic data of the Elderly and Non-Elderly Patient Groups.

\begin{tabular}{|c|c|c|c|}
\hline Parameter & Non-Elderly Group (n:57) & Elderly Group (n:101) & p-value \\
\hline Age [years] & $55.15 \pm 9.57$ & $76.55 \pm 7$ & $<0.001$ \\
\hline Gender n (M/F) & $41 / 16$ & $69 / 32$ & 0.635 \\
\hline BMI [kg/m2] & $24.16(22.49-28.83)$ & $24.91(21.96-26.57)$ & 0.117 \\
\hline $\begin{array}{l}\text { Diagnosis n (\%) } \\
\text { Pneumonia } \\
\text { COPD } \\
\text { PTE } \\
\text { TBC } \\
\text { OHS } \\
\text { IPF exacerbations } \\
\text { Bronchiectasis }\end{array}$ & $\begin{array}{r}38(66.7) \\
13(22.8) \\
4(7) \\
1(1.8) \\
1(1.8) \\
0(0) \\
0(0)\end{array}$ & $\begin{array}{r}65(64.4) \\
20(19.8) \\
7(6.9) \\
2(2) \\
2(2) \\
3(3) \\
2(2)\end{array}$ & $\begin{array}{l}0.770 \\
0.655 \\
0.984 \\
0.920 \\
0.920 \\
0.189 \\
0.285\end{array}$ \\
\hline Comorbidities n (\%) & $54(94.7)$ & $95(94.1)$ & 0.583 \\
\hline $\begin{array}{l}\text { Duration of hospitalization } \\
\text { (days) }\end{array}$ & $12(5-18.5)$ & $12(6-20.5)$ & 0.580 \\
\hline $\begin{array}{l}\text { Vasopressor requirement } \\
\mathrm{n}(\%)\end{array}$ & $11(19.3)$ & $26(25.7)$ & 0.358 \\
\hline Predicted mortality rate & $16.2(10-26.3)$ & $21(11.4-35.6)$ & 0.010 \\
\hline APACHE II score & $13(8.5-17)$ & $15(10.5-20.5)$ & 0.008 \\
\hline IMV n (\%) & $31(54.4)$ & $46(45.6)$ & 0.286 \\
\hline $\begin{array}{l}\text { The duration of staying } \\
\text { intubated (days) }\end{array}$ & $9(4-15)$ & $7.5(2-15.25)$ & 0.685 \\
\hline NIMV n (\%) & $35(61.4)$ & 74 (73.3) & 0.122 \\
\hline $\begin{array}{l}\text { The duration of NIMV } \\
\text { (days) }\end{array}$ & $7(4-12)$ & $9(4.5-18)$ & 0.190 \\
\hline Mortality n (\%) & $14(24.6)$ & $30(29.7)$ & 0.489 \\
\hline
\end{tabular}

M/F: Male/female, BMI: Body mass index, COPD: Chronic obstructive pulmonary disease, PTE: Pulmonary thromboembolism, TBC: Tuberculosis, OHS: Obesity hypoventilation syndrome, IPF: Idiopathic pulmonary fibrosis, APACHE: Acute Physiology, Assessment and Chronic Health Evaluation, IMV: Invasive mechanical ventilation, NIMV: Non-invasive mechanical ventilation.

as $38 \%(7,8)$. Similar ratios have been reported in studies conducted in countries other than Turkey. In the study conducted by Fuchs et al. (10), 45.7\% of patients followed in ICU were aged 65 years or over; whereas, it was reported as $55 \%$ in the study by Angus et al. (11). In our study, the most frequent causes of hospitalization were pneumonia and COPD exacerbations $(65.2 \%$ and $20.9 \%$, respectively) in patients both over and below 65 years of age. Even though cardiovascular disorders have been reported as the leading cause of hospitalization of elderly patients in ICUs (3), patient population varies in accordance with the type of ICU. The most common diagnosis at admission was reported as pneumonia in a study which evaluated 3,050 patients who had been hospitalized in ICUs because of respiratory causes (12). Likewise, Akın et al. (13) reported that the most common diagnosis at admission was pneumonia in patients aged 65 years and over hospitalized in the medical ICU. 
Table 2. The laboratory parameters of the Non-Elderly and Elderly Groups.

\begin{tabular}{|c|c|c|c|}
\hline Parameter & Non-Elderly Group (n:57) & Elderly Group (n:101) & p-value \\
\hline Urea (mg/L) & $47(30-66)$ & $59(38-95)$ & 0.004 \\
\hline Creatine (mg/dL) & $0.69(0.54-0.83)$ & $0.84(0.63-1.3)$ & 0.002 \\
\hline $\operatorname{ALT}(U / L)$ & $21(12.5-36.5)$ & $15(10.5-31)$ & 0.154 \\
\hline AST (U/L) & $23(14.5-42.5)$ & $21(13.5-36)$ & 0.104 \\
\hline T. Bilirubin (mg/dL) & $0.6(0.39-0.79)$ & $0.6(0.4-0.9)$ & 0.493 \\
\hline D. Bilirubin (mg/dL) & $0.28(0.18-0.45)$ & $0.32(0.21-0.54)$ & 0.598 \\
\hline Protein $(\mathrm{g} / \mathrm{dL})$ & $5.65 \pm 0.89$ & $5.72 \pm 0.85$ & 0.597 \\
\hline Albumin (g/dL) & $2.77 \pm 0.61$ & $2.7 \pm 0.54$ & 0.536 \\
\hline $\mathrm{CRP}(\mathrm{mg} / \mathrm{L})$ & $108.51 \pm 86.52$ & $104.84 \pm 74.46$ & 0.993 \\
\hline Procalcitonin (ng/mL) & $0.59(0.1-1.57)$ & $0.26(0.11-0.71)$ & 0.826 \\
\hline 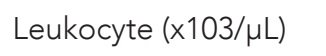 & $11.98 \pm 6.39$ & $13.3 \pm 6.3$ & 0.196 \\
\hline 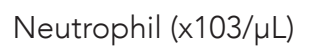 & $10.12 \pm 5.93$ & $11.25 \pm 62.6$ & 0.241 \\
\hline 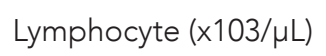 & $1.15(0.5-1.62)$ & $1000(595-1475)$ & 0.270 \\
\hline NLR & $8(5.28-17.29)$ & $9.74(5.79-17.69)$ & 0.882 \\
\hline $\mathrm{Hb}(\mathrm{g} / \mathrm{dL})$ & $10.94 \pm 2.23$ & $10.62 \pm 1.84$ & 0.405 \\
\hline $\operatorname{PLT}(\times 103 / \mu \mathrm{L})$ & $224(163.5-301)$ & $256(190.5-331.5)$ & 0.419 \\
\hline MPV (fL) & $9.73 \pm 1.31$ & $9.79 \pm 1.07$ & 0.598 \\
\hline RDW (\%) & $15.86 \pm 2.54$ & $16.09 \pm 1.9$ & 0.295 \\
\hline $\mathrm{pH}$ & $7.42(7.35-7.48)$ & $7.39(7.30-7.45)$ & 0.036 \\
\hline $\mathrm{PaO} 2(\mathrm{mmHg})$ & $64(56.5-92.9)$ & 67 (57-94) & 0.981 \\
\hline $\mathrm{PaCO} 2(\mathrm{mmHg})$ & $43(35.8-67.25)$ & 48 (37.55-63) & 0.860 \\
\hline $\mathrm{HCO} 3(\mathrm{mEq} / \mathrm{L})$ & $29(25-34)$ & $27(23-31)$ & 0.068 \\
\hline $\mathrm{SaO} 2(\%)$ & $92.5(89-96)$ & 93 (87.5-96.5) & 0.259 \\
\hline
\end{tabular}

ALT: Alanine aminotransferase, AST: Aspartate aminotransferase, T: Total, D: Direct, CRP: C-reactive protein, NLR: Neutrophil / lymphocyte ratio, Hb: Hemoglobin, PLT: Platelet, MPV: Mean platelet volume, RDW: Red cell distribution width, (PaO2): Partial oxygen pressure, (PaCO2): Partial carbon dioxide pressure, $\mathrm{HCO} 3$ : Bicarbonate, $(\mathrm{SaO} 2)$ : Oxygen saturation. 
Table 3. The laboratory parameters of the Non-Elderly and Elderly Groups.

\begin{tabular}{|l|r|r|r|r|}
\hline Risk factor & OR & Lower & Upper & p-value \\
\hline APACHE II & 0.852 & 0.771 & 0.942 & 0.002 \\
\hline Hypoalbuminemia & 23.430 & 4.504 & 121.871 & $<0.001$ \\
\hline $\begin{array}{l}\text { Vasopressor } \\
\text { requirement }\end{array}$ & 6.448 & 1.674 & 24.837 & 0.007 \\
\hline
\end{tabular}

APACHE: Acute Physiology, Assessment and Chronic Health Evaluation

Because our study was conducted in the respiratory ICU, our patient population most commonly comprised patients hospitalized for pneumonia and COPD exacerbations.

Various studies have reported that the mortality rate is higher in elderly patients hospitalized in ICUs $(7,10,14)$. In a study by Rosenthal et al. (15), age was reported to be related to mortality, independent of the severity of the disease and other prognostic factors. Likewise, in a study by Hamel et al. (16), it was reported that mortality increased with age after correction of various parameters such as gender, race, baseline functional status, disease severity, aggressiveness of treatment, and socio-economic status. However, even though the predicted mortality rate and the APACHE II score were significantly higher in patients aged 65 years and over in our study, the mortality rates of both groups were similar. There are also studies in the literature stating that age is not separately effective on mortality $(13,17,18)$. In various studies, it has been reported that age was not associated with poor prognosis in ICU patients, and prognosis was more likely related to disease severity and functional status before the onset of the disease $(19,20)$. We also consider that the severity of the underlying disease more likely affects mortality rather than age and believe that with appropriate treatment and follow-up, mortality in elderly patients would be the same as in young patients.

In our study, the mortality rate was found to be $24.6 \%$ in patients under 65 years of age and $29.7 \%$ in those aged 65 years and over; the overall mortality rate was $27.8 \%$. Different mortality rates have been reported in the literature. In a study by Rockwood et al. (21), the 1-year mortality was reported as 31\% and $49 \%$ under and over 65 years of age, respectively. In a study conducted by Topeli et al. (6), the mortality rate was found as $32.5 \%$ in patients younger than 65 years and $38.7 \%$ in patients aged 65 years and over. The higher mortality rates in these studies may be due to the heterogeneity of patients followed in ICUs. Moreover, the mortality rate in ICU varies according to the characteristics of the followed patient population and the experience of the healthcare staff. Following a similar patient group in ICU would contribute to achieve a more experienced ICU healthcare staff, which would cause a positive effect on patient recovery. In a study by Doğan et al. (7), it was determined that while the mortality rate was $54.6 \%$ in 2008, it decreased to $33.1 \%$ with turning over the management of ICU to Anesthesiology Department in 2009.

In our study, when the laboratory data were analyzed, it was found that the urea and creatine values were higher and the $\mathrm{pH}$ was lower in the Elderly group. We suggest that these may have originated from impairment of renal function and its related effect on blood gases with advanced age. It has been shown in the medical literature that renal functions and blood gas parameters 
were affected in elderly patients (22). The association of hypoalbuminemia with mortality has been shown before (23). In our study, hypoalbuminemia was determined to be an effective factor in mortality, which was in accordance with the literature. The APACHE II scoring system is a significant predictor of mortality (9). In the study conducted by Rordorf et al., it was shown in intensive care patients that the APACHE II score was a predictor of mortality (24). In our study also, the elevation of the APACHE II score was determined to be a factor effective on mortality. The requirement of VP support in patients during the follow-up period in ICU indicates a hemodynamic disorder and has

\section{REFERENCES}

1. Lunenfeld B, Stratton P. The clinical consequences of an ageing world and preventive strategies. Best Pract Res Clin Obstet Gynaecol 2013;27(5):643-59. (PMID:23541823).

2. Turkish Statistical Institute. Eldery with Statistics, 2018. Turkey Statistical Institute Newsletter 2018;30699. [Internet] Available from: http://www.tuik.gov. tr/PreHaberBultenleri.do?id=30699. Accessed: 18.03.2019.

3. Bagshaw SM, Webb SA, Delaney A, et al. Very old patients admitted to intensive care in Australia and New Zealand: a multi-centre cohort analysis. Crit Care 2009;13(2):45. (PMID:19335921).

4. Yu W, Ash AS, Levinsky NG, Moskowitz MA. Intensive care unit use and mortality in the elderly. J Gen Intern Med 2000;15(2):97-102. (PMID:10672112).

5. Hennessy D, Juzwishin K, Yergens D, Noseworthy T, Doig C. Outcomes of elderly survivors of intensive care: a review of the literature. Chest 2005;127(5):176474. (PMID:15888857).

6. Topeli A. The outcome of the geriatric patients in the ICU. Crit Care 2001;5(1):249.

7. Doğan S, Can H, Doğan N, Gönüllü M. Comparison of the Mortality Rates for Patients Aged 65 Years and Over and Aged Below 65 Years, Hospitalized in the Intensive Care Unit. J Med Sci 2013;33(6):1408.

8. Uysal N, Gundogdu N, Borekci Ş, et al. Prognosis of Patients in a Medical Intensive Care Unit of a Tertiary Care Centre. Turkish Journal of Intensive Care been reported to be associated with mortality (25). In our study also, we determined that the requirement of VP support affected mortality.

As a conclusion, we suggest that the albumin level, APACHE II score, and VP requirement should be used rather than age for prediction of mortality in patients followed up in the respiratory intensive care unit, and more detailed studies should be conducted on this subject.

\section{Conflicts of interest}

The authors of this article state that they have no conflict of interest.

Medicine 2010;1:1-5.

9. Knaus WA, Draper EA, Wagner DP, Zimmerman JE. APACHE II: a severity of disease classification system. Crit Care Med 1985;13(10):818-29. (PMID:3928249).

10. Fuchs $L$, Chronaki CE, Park $S$, et al. ICU admission characteristics and mortality rates among elderly and very elderly patients. Intensive Care Med 2012;38(10):1654-61. (PMID:22797350).

11. Angus $D C$, Barnato $A E$, Linde-Zwirble $W T$, et al. Use of intensive care at the end of life in the United States: an epidemiologic study. Crit Care Med 2004;32(3):638-43. (PMID:15090940).

12. Heuser MD, Case LD, Ettinger WH. Mortality in intensive care patients with respiratory disease. Is age important? Arch Intern Med 1992;152(8):1683-8. (PMID:1497402).

13. Akın $S$, Gundogan K, Coskun R, et al. Critically III Elderly Patient Mortality: Is Age a Risk Factor? Turkish Journal of Intensive Care Medicine 2014;5:26-9.

14. Vosylius S, Sipylaite J, Ivaskevicius J. Determinants of outcome in elderly patients admitted to the intensive care unit. Age Ageing 2005;34(2):157-62. (PMID:15713860).

15. Rosenthal GE, Kaboli PJ, Barnett MJ, Sirio CA. Age and the risk of in-hospital death: insights from a multihospital study of intensive care patients. J Am Geriatr Soc 2002;50(7):1205-12. (PMID:12133014).

16. Hamel MB, Davis RB, Teno JM, et al. Older age, 
aggressiveness of care, and survival for seriously ill, hospitalized adults. SUPPORT Investigators. Study to Understand Prognoses and Preferences for Outcomes and Risks of Treatments. Ann Intern Med 1999;131(10):721-8. (PMID:10577294).

17. Stephan F, Cheffi A, Bonnet F. Nosocomial infections and outcome of critically ill elderly patients after surgery. Anesthesiology 2001;94(3):407-14. (PMID:11374598).

18. Leong IY, Tai DY. Is increasing age associated with mortality in the critically ill elderly. Singapore Med J 2002;43(1):33-6. (PMID:12008774).

19. de Rooij SE, Govers A, Korevaar JC, Abu-Hanna A, Levi $\mathrm{M}$, de Jonge $\mathrm{E}$. Short-term and long-term mortality in very elderly patients admitted to an intensive care unit. Intensive Care Med 2006;32(7):1039-44. (PMID:16791666).

20. Kaarlola A, Tallgren M, Pettila V. Long-term survival, quality of life, and quality-adjusted life-years among critically ill elderly patients. Crit Care Med 2006;34(8):2120-6. (PMID:16763517)

21. Rockwood K, Noseworthy TW, Gibney RT, et al. One- year outcome of elderly and young patients admitted to intensive care units. Crit Care Med 1993;21(5):68791. (PMID:8482089).

22. Yokota LG, Sampaio BM, Rocha EP, Balbi AL, Sousa Prado IR, Ponce D. Acute kidney injury in elderly patients: narrative review on incidence, risk factors, and mortality. Int J Nephrol Renovasc Dis 2018;11:21724. (PMID:30147352).

23. Viasus D, Garcia-Vidal C, Simonetti A, et al. Prognostic value of serum albumin levels in hospitalized adults with community-acquired pneumonia. J Infect 2013;66(5):415-23. (PMID:23286966).

24. Rordorf G, Koroshetz W, Efird JT, Cramer SC. Predictors of mortality in stroke patients admitted to an intensive care unit. Crit Care Med 2000;28(5):13015. (PMID:10834669).

25. Li G, Cook DJ, Thabane L, et al. Risk factors for mortality in patients admitted to intensive care units with pneumonia. Respir Res 2016;17(1):80. (PMID:27401184). 